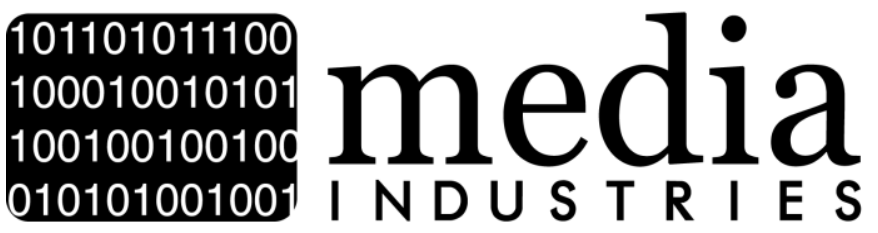

\title{
Welcome to the Unregulated Wild, Wild, Digital West
}

\author{
Denise Mann ${ }^{1}$ \\ University of California, Los Angeles \\ Dmann [AT] tft.ucla.edu
}

\begin{abstract}
:
An impasse between Hollywood and Silicon Valley over streaming rights to home entertainment has created a power vacuum, prompting a number of virtual entrepreneurs to look for alternative ways to monetize online media. This essay examines the "transmedia" industries and multichannel networks as transitional workspaces-innovative new forms of industrial organization, emerging forms of creative work, new technologies and economic models, and creative relations among consumers, marketers, and producers. A number of cultural industries scholars are engaged in productive critiques of digital media labor practices. ${ }^{2}$ In contrast, humanities-based critical and cultural studies scholars tend to ignore the economic realities of web-based production, focusing instead on the unpaid (albeit volunteer) labor of fans. Far fewer consider the more widespread, invisible labor associated with the wholesale data mining of consumer preferences that are being sold en masse to advertisers by major internet technology companies like Google and Facebook. Even fewer explore the paradox of YouTube talent partners, who eschew deals with Hollywood to avoid creative interference but tolerate Faustian deals with Google to profit from surveillance-based advertising.
\end{abstract}

Keywords: Advertising, Hollywood, Labor, Marketing, Social Media

Google, Microsoft, Apple, and the other internet technology giants desperately want to control Hollywood's premium content, seeing it as the crown jewel in their massive marketing infrastructure via a vast array of smart, mobile technologies and social networking capabilities. However, the internet giants' failure to wrest control over the studios' content business stems from an inherent misunderstanding of the Hollywood system-its inscrutable rules of engagement, rigid hierarchies, and fixed allegiances to strategic partners. Recognizing this impasse between the two sets of corporate behemoths as an opportunity to advance a new culture industry-one less bound by old-fashioned bureaucracies - two types of web-based para-industrial start-ups have emerged with distinct approaches to monetizing the internet. They are the transmedia producers/digital marketing gurus, such as Starlight Runner 
Entertainment, 42 Entertainment, and Campfire, and the multichannel networks (MCNs), such as Fullscreen, Maker Studios, and Machinima. The MCNs aggregate large numbers of YouTube talent partners as a way to maximize their share of YouTube advertising revenues; in contrast, a number of "independent" web companies (Funny or Die, College Humor, the Collective, Break Media, and Alloy Digital) differentiate themselves from the MCNs by retaining in-house advertising sales teams, production personnel, and their own streaming websites - all strategies designed to make them less dependent on YouTube's revenue-sharing arrangement. ${ }^{3}$ However, for the purposes of this article, both types of web-only production companies will be referred to as MCNs, given their joint interest in aggregating web content to attract online advertising dollars in the still-unregulated space of the internet. In exchange for the right to place ads, the MCNs underwrite the production of original, short-form web content, granting creators a degree of creative autonomy rarely seen in Hollywood. Prominent examples of inventive, original web content include Break Media's Man at Arms (2013) , Maker Studios' Epic Rap Battles (2010 - present), and the Collective's Annoying Orange (2009-2012).

The transmedia producers, such as Starlight Runner Entertainment and 42 Entertainment, and digital marketers, such as Campfire, are distinct from the MCNs in their approach to reinventing traditional entertainment. Most transmedia producers and digital marketers produce promotional paratexts on behalf of the Hollywood media groups in support of their major media franchises; these indirect, story-driven marketing campaigns are more in line with millennial consumers' tastes than hard-sell approaches are. ${ }^{4}$ The transmedia producers have learned to insert themselves in once-immutable studio divisions-licensing, marketing, consumer products - by providing executives with detailed "story bibles" to facilitate oversight of the licensed vendors responsible for designing paratexts. Notably, the transmedia producers are often accused of being marketers rather than creators. However, they have deliberately chosen an alternative path to that of the traditional Hollywood producer, who pitches and packages original projects for presentation to the studios and networks (a process with a high rate of failure and creative micromanagement). Innovative examples of cutting-edge promotional content created by transmedia producers and digital marketers include 42 Entertainment's Why So Serious? (2008), an alternate-reality game created to hype Warner Bros.' The Dark Knight (2008), and Campfire's “The Five Senses" (2011) campaign, created to tout HBO's drama series Game of Thrones (2011 - present). ${ }^{5}$ Despite their differences, the transmedia production companies and MCNs are all focused on producing content-promotional hybrids that are designed to be spread by consumers across a variety of social networks (Facebook, Twitter). This consumer-driven distribution helps these hybrid productions rack up maximum "hits," akin to a virtual pinball machine, thereby unleashing a steady stream of Google AdSense earnings for both their creative and brand partners. By enacting this revised media economy inviting unpaid users to share web promotions and become fans of brands - these transitional production companies have devised a new, advertising-infused culture-industry model that is potentially far more potent than broadcasting's thirty-second ads. As Siva Vaidhyanathan explains in The Googlization of Everything, the "product" that is being exploited is the online consumer, who spreads the marketing message among his or her social network of friends and colleagues, producing a vast, exponential reach. ${ }^{6}$ Think internet meme Harlem Shake (2013); its creator, Filthy Frank, was not paid a dime, while the web-based companies that facilitated its spread across the globe all raked in major profits. Scary business, indeed, as Google's deep infrastructural roots make it the ultimate benefactor of all this sharing and data mining. 
Until recently, Google (YouTube's parent company) was largely content agnostic - not caring about the quality of YouTube's user-generated content except as an additional means to generate search-driven "hits." An industrial sea change occurred from 2011 and 2013 when Google-YouTube infused \$200 million in production funding into its most successful talent partners as a means of achieving higher advertising rates. The MCNs facilitated this push toward higher production values by forging contractual agreements with YouTube talent partners in exchange for production facilities, social marketing tools, and other resources. In reality, the MCNs only provide production resources for their most successful creators. Paradoxically, it is this same group of web celebrities that tends to accuse the MCNs of exploitative labor practices and to use social media to publicly decry the onerous terms of their agreements, which, in the case of Maker Studios, grants creators 40 percent of shared advertising revenues and 50 percent of the intellectual property rights for their productions in perpetuity. ${ }^{7}$ The MCNs counter by arguing that they sink the majority of their profits back into the web productions of their talent partners.

While the transmedia producers and MCNs described above are engaged in the risky business of reinventing content creation for the digital economy, the tech giants-Apple, Microsoft, Google, Intel, and Sony - are pursuing a much bigger prize by seeking to control streaming distribution rights to all content delivered to the home. Over its hundred-year history, Hollywood has profited by controlling the copyrights on all its premium content, which are leveraged to the tune of $\$ 300$ billion a year in combined US and European revenues by exploiting a series of windows: DVD/VHS, pay TV, streaming video on demand (SVOD), cable or satellite, broadcast television, the syndicated television markets, and so forth. ${ }^{8}$ Despite the marketing fanfare and expense associated with studio theatrical releases, the latter serve primarily as loss leaders that are designed to encourage consumers to rent, buy, or subscribe to watch the content on one or more of the exploitation windows. One of the biggest threats to the traditional Hollywood industry is the potential collapse of these windows as cord-cutting consumers demand that premium content be made accessible online and all at once, also known as "television everywhere." The various tech giants - in particular, Apple, Microsoft, and Google-have made several bold efforts to control the delivery of Hollywood's premium content online via their new smart technologies - Apple TV, Microsoft Xbox, and Google TVwith various degrees of success. Presently, the dominant players in this space are the multichannel video program distributors (MVPDs), in particular, the cable and satellite carriers. As more consumers adapt to smart TVs with built-in Wi-Fi or user-friendly smart-TV interfaces such as Roku and Google's Chromecast, Hollywood licensors may shift from set-top boxes (provided by the MVPDs) to over-the-top, SVOD services such as Netflix, Hulu Plus, and Amazon Prime. The MCNs are eager to position themselves as the primary web content providers of the future, in part by forging deals with the traditional distributors and the new SVOD sites. However, the internet technology companies stand to control the entire Monopoly gameboard by retaining streaming distribution rights to all content via their combined hardware (smart TVs) and software (mobile apps, advertising products) capabilities. By controlling all on-demand entertainment streamed to the home, Google, for instance, could extract an even larger share of its current search-driven, global consumer marketing business.

This brief survey of two para-industries - transmedia producers and MCNs - reveals two sides of the same risky production coin, each group trying to turn web content creation into a viable business. In fact, the ultimate benefactors of this unregulated Wild, Wild, Digital West are 
Google, Facebook, and other internet technology companies that have turned their surveillancedriven brand-marketing businesses into a multibillion-dollar industry. In Cultural Industries, David Hesmondhalgh addresses the game-changing shift that YouTube introduced to the webbased creative industries by launching a new hybrid cultural form - or what legal scholar and intellectual property activist Lawrence Lessig calls a new hybrid economy-based on a community where people interact on terms "which are commerce free, though the motivations for interacting may or may not tie into commerce." 9 Clearly, the days of a commercial-free web zone are gone as companies and creators partner to earn their share of online advertising profits. In the still-unregulated space of the new economy, Google (part of what Jennifer Holt dubbed the "access of evil") has motivated purportedly maker-friendly companies like Maker Studios to bilk their creative partners out of their share of what has become the new-economy equivalent of Monopoly money - AdSense dollars. ${ }^{10}$ Some humanities-based scholars focus only on the text-based attributes of prosumer culture celebrate YouTube's "democratic" broadcast system and rejoice in its $\$ 200$-million-plus investment in its content partners. These scholars risk losing sight of the larger social themes on display - the emergence of a new culture industry dependent on invasive surveillance systems that cast consumers in the role of invisible labor as their consumer preferences are aggregated and sold to advertisers.

As media industry scholars, we need to be mindful of the exploitative practices on display in these new media practices. We should question user-generated-content creators who have been trained by YouTube and its MCN partners to focus on achieving celebrity by any means necessary in order to increase their user count and, hence, their share of AdSense dollars. While the Hollywood media companies are the frequent target of Marxist-themed critiques - from the Frankfurt School, cultural studies, and more recent cultural industries scholarship - the recent collection assembled by Trebor Scholz, Digital Labor: The Internet as Playground and Factory, is particularly useful in exposing the dark economy of the internet. ${ }^{11}$ Certainly, a fruitful area for future research is the practice of web-based companies hiring semiskilled digital laborers who become knowing partners in these exploitative practices. ${ }^{12}$

1 Denise Mann is an associate professor in the UCLA School of Theater, Film, and Television and head of the UCLA Producers Program (1996-present). Mann is the editor of Wired TV: Laboring over an Interactive Future (2014); the author of Hollywood Independents: The Postwar Talent Takeover (2008); and the co-editor of Private Screenings: Television $\mathcal{E}$ the Female Consumer (1992). She served as an associate editor on Camera Obscura: A Journal of Feminism and Film Theory (1986-1992). With Professor Henry Jenkins, Mann co-chairs the annual "Transmedia, Hollywood" conference (2010present), which brings together cutting-edge scholars, industry professionals, and creators to debate the future of entertainment.

2 David Hesmondhalgh, The Cultural Industries (London: Sage, 2013); Terry Flew, The Creative Industries: Culture and Policy (London: Sage, 2012).

3 In late 2013, Break Media and Alloy Digital merged to become Defy Media, combining Break's young male audience with Alloy's young female audience.

${ }^{4}$ Michael Serazio, Your Ad Here: The Cool Sell of Guerilla Marketing (New York: New York University Press, 2013). Also see Jonathan Gray, Show Sold Separately: Promos, Spoilers, and Other Media Paratexts (New York: New York University Press, 2010). 
${ }^{5}$ Frank Rose, “. . . And the Final Lesson from 'Game of Thrones' Is, 'Always Support the Bottom," Deep Media, January 30, 2012.

6 Siva Vaidhyanathan, The Googlization of Everything: (And Why We Should Worry) (Berkeley: University of California Press, 2010).

7 Tessa Stuart, "YouTube Stars Fight Back: Machinima and Maker Studios, Two of YouTube's Most High-Profile Networks, Have Come under Fire from Their Own Talent," LA Weekly January 10, 2013.

8 Guy Di Piazza and Martin Olausson, "The Television and Movie Industry Explained: Where Does All the Money Go?" Digital Media Strategies Service, June 2007

${ }^{9}$ Hesmondhalgh, Cultural Industries, 351.

10 Jennifer Holt, "Access of Evil: Google, Verizon and the Future of Net Neutrality," In Media Res, August 25, 2010.

11 Trebor Scholz, ed., Digital Labor: The Internet as Playground and Factory (New York: Routledge, 2013).

12 The themes in this essay are drawn from my forthcoming book Advertaining America: At Work and Play in the Digital Economy.

\section{Bibliography}

Di Piazza, Guy, and Martin Olausson. "The Television and Movie Industry Explained: Where Does All the Money Go?" Digital Media Strategies Service, 2007.

Flew, Terry. The Creative Industries: Culture and Policy. London: Sage, 2012.

Gray, Jonathan. Show Sold Separately: Promos, Spoilers, and Other Media Paratexts. New York: New York University Press, 2010.

Hesmondhalgh, David. The Cultural Industries. London: Sage, 2013.

Holt, Jennifer. “Access of Evil: Google, Verizon, and the Future of Net Neutrality." In Media Res, August 25, 2010.

Rose, Frank. ". . . And the Final Lesson from 'Game of Thrones' Is, 'Always Support the Bottom.'" Deep Media, January 30, 2012.

Scholz, Trebor. Digital Labor: The Internet as Playground and Factory. New York: Routledge, 2013.

Serazio, Michael. Your Ad Here: The Cool Sell of Guerilla Marketing. New York: New York University Press, 2013.

Stuart, Tessa. "YouTube Stars Fight Back: Machinima and Maker Studios, Two of YouTube's Most High-Profile Networks, Have Come under Fire from Their Own Talent." LA Weekly, January 10, 2013.

Vaidhyanathan, Siva. The Googlization of Everything: (And Why We Should Worry). Berkeley: University of California Press, 2010. 
Media Industries Journal 1.2 (2014), ISSN 2373-9037

\section{(cc) EY-NC-ND}

Copyright (C) 2014 (Denise Mann). Media Industries is an open-access, peer-reviewed, online academic journal. As such, we aim to participate in the open exchange of information. This work is licensed under a Creative Commons Attribution Noncommercial No Derivatives (by-nc-nd) License. Under this license, this work is available for sharing and noncommercial distribution provided the appropriate attribution is given. 